\title{
Edublogs musicales en el tercer ciclo de educación primaria: perspectiva de alumnos y profesores
}

\section{Music blogs in the third cycle of primary education: perspective of students and teachers}

\author{
Sonia ROMERO MARTÍNEZ y Manuel VELA BARRANCO \\ Universidad a Distancia de Madrid
}

Recibido: Febrero 2013

Aceptado: Abril 2013

\begin{abstract}
Resumen
Este estudio tiene como objetivo analizar el uso del blog como recurso educativo en el proceso de enseñanza-aprendizaje de la asignatura de música en el tercer ciclo de educación primaria. Los participantes han sido 6 maestros y 178 alumnos de varios colegios españoles que tienen en marcha un blog para el desarrollo de la clase. Respecto a los alumnos, se ha realizado un cuestionario online a partir del cual se describe la motivación, actitudes y expectativas con respecto al blog y se estudia la relación de dichas variables con características como edad, género, gusto por la música y nota en la asignatura. Con respecto a los profesores se ha realizado una entrevista estructurada atendiendo a sus opiniones, expectativas y sugerencias con respecto al uso de la herramienta. Los resultados muestran una alta valoración del blog en los dos colectivos estudiados. Las asociaciones entre variables mediante la prueba chi-cuadrado muestran que a mayor tiempo de utilización del blog mayor interés por las TIC $\left(\mathrm{x}^{2}=23,43 ; \mathrm{gl}=\right.$ 4 ; $p<0.05)$, mayor uso de Internet $\left(\mathrm{x}^{2}=23,43 ; \mathrm{gl}=4 ; p<0.05\right)$ y mejores notas en música $\left(\mathrm{x}^{2}=\right.$ $17,74 ; \mathrm{gl}=8 ; p<0.05)$. Por otra parte, los resultados de la prueba de Mann-Whitney indican que no hay diferencias significativas entre sexos ni por edades en ninguna de las tres escalas (motivación, actitudes y preferencias) pero sí las hay con respecto a la experiencia con el blog y al gusto por la música siendo en todos los casos mayor la valoración en los grupos con más experiencia en el blog y con mayor gusto por la música. Finalmente se han analizado las respuestas de los profesores en las siguientes categorías: argumentos ofrecidos para la creación del blog, metodología, ventajas e inconvenientes, participación, mejoras y potencial.
\end{abstract}

Palabras clave: Blog, Educación Musical, Tecnologías de la Información y Comunicación (TIC), Educación Primaria, Alumnos, Profesores

\footnotetext{
Abstract

The aim of the present work is to analyse the use of blogs as educational resources in the process of teaching-learning in the music class in the third cycle of primary education in Spain. Participants are 6 teachers and 178 students of several schools that use blogs to develop the music class. Students responded an online questionnaire in order to describe motivation, attitudes and expectations regarding the blog and to study its relationship with characteristics 
such as gender, age, love for music and grades in music. Regarding to teachers, a structured interview was conducted asking them about their opinions, expectations and suggestions with respect to the use of the tool. The results reveal a high valuation of the blog in both cohorts. Association between variables, by the chi-squares test, shows: the more time using the blog, the more interest in new technologies $\left(\mathrm{x}^{2}=23,43 ; \mathrm{gl}=4 ; p<0.05\right)$, the more Internet use $\left(\mathrm{x}^{2}=\right.$ $23,43 ; \mathrm{gl}=4 ; p<0.05)$ and the better grades in music $\left(\mathrm{x}^{2}=17,74 ; \mathrm{gl}=8 ; p<0.05\right)$. On the other hand, the results of Mann-Whitney test indicate no significant differences in the valuation of the blog according to gender or age, but there are differences according to experience with the blog use and love for music, being high the mean valuation in the groups with more experience and more love for music. Finally the response of teachers were analysed according to the following categories: arguments offered for the creation of the blog, methodology, advantages and disadvantages, participation, and potential improvements of the blog.

Keywords: Blog, Musical Education, Information and Communication Technologies [ICT), Primary Education, Students, Teachers

La sociedad ha estado sumergida desde su nacimiento en un constante cambio evolutivo. Ha pasado por diferentes etapas sociales, cada una de ellas definida por una serie de características propias que la determina. Esa evolución tiene como último eslabón a la Sociedad de la Información, sociedad que se caracteriza, entre otras cosas, por la omnipresencia de las Tecnologías de la Información y la Comunicación (en adelante TIC). Estas tecnologías se utilizan de manera individual, pero también, y lo que es más importante, se utilizan complementándose unas con otras consiguiendo sacar el máximo provecho posible.

Adell (1997) hace quince años indicaba que las TIC habían llevado a que se transformara la manera de actuar de las personas, de hacer las cosas. Tres lustros son poco tiempo, pero la incorporación de estas herramientas en ese corto período ha sido inmensa. Se ha pasado de una web estática a una web dinámica, de la Web 1.0 a la Web 2.0. Esto ha llevado consigo que las personas no sólo sean consumidoras, sino también productoras de información, ya no son meras espectadoras; aunque no todas tienen el mismo grado de producción, algunas ni siquiera pueden ser consumidoras debido a la brecha digital existente (Bimber, 2000; Bonfadelli, 2002). Además aparecen nuevos aparatos tecnológicos que se van incorporando en nuestras vidas en mayor o menor medida (DiMaggio, Hargittai, Neuman \& Robinson, 2001).

En la escuela, institución a la que se vincula el presente trabajo, se han estado incorporando poco a poco las TIC. Una de las herramientas que nos ofrece internet más presente en ella es el blog. Martínez y Hermosilla (2010) definen el blog como "un formato de publicación web que se actualiza periódicamente y en el que se recopilan cronológicamente textos o artículos de uno o varios autores" (p. 166). Cuando el blog tiene como objetivo contribuir al proceso de enseñanza-aprendizaje se denomina edublog.

Esta herramienta está muy presente en la educación y en diferentes niveles. Sirva como ejemplo que en el VI Premio Espiral de Edublogs (2012) se presentaron 1824 
edublogs. Muchos docentes se sirven de ellos en sus clases, de una manera u otra, con más o menos importancia. Lara (2005) deja ver que los blogs son una herramienta de la Web 2.0 no sólo aplicable a cualquier campo (la educación, el periodismo, etc.), sino también a diversas materias y edades: "los weblogs tienen un gran potencial como herramienta en el ámbito de la enseñanza, ya que se pueden adaptar a cualquier disciplina, nivel educativo y metodología docente" (p.25). Existe así un buen medio de enseñanza, pero es necesario trabajar con él de manera adecuada. Es decir, utilizar las TIC de manera reflexiva, crítica, pensando qué se quiere conseguir, para qué se va a utilizar, cómo, etc. Según Giráldez (2010) "no basta con introducir tecnologías en las aulas. Antes de hacerlo es necesario definir el nuevo perfil del alumnado y la función y finalidad de dichas tecnologías en los procesos de enseñanza y aprendizaje" (p.74).

En relación a investigaciones sobre edublogs, Durán (2010) indica, entre otras conclusiones, que el blog estimula el seguimiento de la asignatura y fomenta la participación de los estudiantes en la misma. Un dato interesante de esta investigación es que el $89,2 \%$ de los participantes otorga una valoración al blog como herramienta educativa de seis a diez puntos. Esta investigación fue realizada con alumnos de diversos niveles educativos. Santos y Fernández (2012), en una investigación donde participaron estudiantes de $4^{\circ}$ de ESO, refleja buenas opiniones por parte de los alumnos. En otras investigaciones con alumnos universitarios, como la de Molina et al. (2013), García y García (2012), Yang y Chang (2012) y Du y Wagner (2005), se muestran resultados positivos de cara al uso de blog en contextos educativos. Domingo y Marqués (2013), en una investigación realizada en centros de Educación Primaria y Secundaria, aportan datos positivos tanto por parte del alumnado como del profesorado en el uso de las TIC en el aula.

Por otra parte, actualmente, la educación musical no se entiende desde una perspectiva donde lo primordial sea una asombrosa técnica instrumental y unos vastos conocimientos de teoría musical por parte del alumnado. Así, Frega (2005) refleja que "La música en la educación general (...) no apunta a la formación de especialistas en un área dada, sino a la promoción del desarrollo pleno de las facultades totales del hombre, siempre en orden al pleno aprovechamiento personal y colectivo de las potencialidades individuales" (p.20). En la escuela no sólo se aprende a tocar la flauta; los alumnos se introducen en la expresión corporal, instrumental, vocal, en la creación musical, en una escucha activa, etc. y resulta fundamental la educación musical integral. Son diversos autores los que han indicado que el objetivo primordial de la educación musical en la actualidad es el de despertar y desarrollar todas las facultades del ser humano (Willems, 1994; Maneveau, 1993; Hemsy de Gainza, 1964 y 1984; Frega, 1978 y Saitta, 1978, entre otros). Pero en relación al tema que nos ocupa, tal y como reflejan Lizaso y García (2012) "consideramos los edublogs como un complemento y una herramienta útil en el proceso de educación musical pero nunca como un sustitutivo de la actividad musical en el aula" (p.68). Veremos más adelante que los alumnos también comparten esta idea.

Debido a la presencia del blog en educación, a las experiencias llevadas a cabo por docentes y alumnos y a resultados positivos en algunas investigaciones previas, resulta de interés profundizar en la perspectiva del alumnado y del profesorado con el objetivo 
de mejorar la utilización de esta herramienta en el proceso de enseñanza-aprendizaje de la música.

Es por este motivo que el objetivo principal de este trabajo es analizar el uso del blog como recurso educativo en el proceso de enseñanza-aprendizaje de la asignatura de música.

La pregunta-problema que orienta el presente estudio es: ¿el edublog como recurso educativo potencia el proceso de enseñanza-aprendizaje en la asignatura de música con alumnos de tercer ciclo de educación primaria?

Los objetivos específicos de la investigación, con respecto a los alumnos son: a) describir la motivación, actitudes y expectativas de los alumnos con respecto al uso de los edublogs en la asignatura de música, b) estudiar la relación de variables características de los alumnos (edad, género, gusto por la música, rendimiento en la asignatura y experiencia con el blog) con la motivación, actitudes y expectativas de los alumnos respecto al blog.

Con respecto a los profesores los objetivos son: a) describir la metodología que los maestros llevan a cabo en la utilización de edublogs musicales; b) recopilar las experiencias que ha suscitado la introducción de la herramienta edublog en la clase de música y c) reflejar aspectos de mejora partiendo de dicha experiencia

Finalmente, otro de los objetivos ha sido elaborar instrumentos (cuestionarios y entrevista estructurada) para recabar opiniones, preferencias y sugerencias de los dos colectivos con respecto a la introducción de esta herramienta en la clase de música.

La hipótesis general que orienta el presente trabajo es que el blog es una herramienta TIC que favorece el proceso de enseñanza-aprendizaje de música en alumnos de tercer ciclo de educación primaria. Esta hipótesis se desglosa en hipótesis específicas de los dos colectivos que participan en el estudio.

Con respecto al alumnado se tienen las siguientes hipótesis: a) el nivel de motivación de los alumnos en la clase de música es alto debido a la utilización del edublog b) los alumnos tienen un nivel de actitud y expectativas favorable con respecto al uso del edublog, c) los alumnos prefieren utilizar el blog a los métodos tradicionales de enseñanza de la música, d) no hay diferencias de acuerdo a la edad o el género en la motivación, actitud y expectativas respecto al edublog, e) hay diferencias de acuerdo al resto de las variables (gusto por la música, rendimiento en la asignatura y experiencia con el edublog) en la motivación, actitud y expectativas respecto al edublog.

La hipótesis específica respecto al profesorado es, como ya se ha comentado, que la introducción del edublog en la asignatura de música, teniendo en cuenta en la metodología el perfil del alumnado y con una función y finalidad clara enriquece el proceso de enseñanza-aprendizaje. 


\section{Método}

\section{Participantes}

La investigación que se ofrece ha podido desarrollarse gracias a la participación de seis maestros y de ciento setenta y ocho alumnos en el tercer trimestre del curso 2011/2012. El muestreo ha sido no probabilístico, principalmente "bola de nieve". Han participado maestros y alumnos de diferentes provincias españolas. Los maestros que aquí aparecen hacen un uso más o menos regular de su edublog y son:

- Luis Belmonte, CEIP Tucci, Martos (Jaén). http://donlumusical.wordpress.com/

- Juan José Flores, CEIP Menéndez y Pelayo, Valverde del Camino (Huelva). http://tatarachin.blogspot.com.es/

- Mary Paz García, CEIP Miguel de Unamuno, Peñaranda de Bracamonte (Salamanca). http://musicamarypaz.blogspot.com.es/

- María de Gregorio Ortego, C.E.I.P. Virgen del Rivero, San Esteban de Gormaz (Soria). http://ponlemusicaatuvida.blogspot.com.es/

- Edison González, Escola Puigsoler, Sant Vicenç de Castellet (Barcelona). http://blocs.xtec.cat/musicaidansa/

- Flora Terensi, Escola Ausiàs March, L’Hospitalet de Llobregat (Barcelona). http://blocs.xtec.cat/amlescortsmusica/

Todos estos maestros participaron en la entrevista, pero varios de ellos, por diversos motivos no pudieron comprometerse a la realización del cuestionario por parte de su alumnado.

\section{Instrumentos}

Los instrumentos utilizados han sido un cuestionario online para el alumnado ${ }^{1}$ (anexo 1) y una entrevista estructurada para el profesorado (anexo 2). El cuestionario del alumnado está formado por siete dimensiones: datos generales (principalmente variables sociodemográficas), actitudes, opiniones, expectativas, preferencias, sugerencias y motivación en relación al edublog. El mismo fue realizado de manera online a través de Google Docs (actualmente Google Drive) y la inmensa mayoría del alumnado contestó a él en horario escolar y con el maestro de la asignatura de música.

En un primer momento, antes que los alumnos realizaran el cuestionario online se llevó a cabo una prueba piloto, con el objetivo de probar la fiabilidad de la escala de Motivación. En esta prueba piloto participaron 43 alumnos, de $5^{\circ}$ y $6^{\circ}$ curso de entre 10 y 13 años. La prueba se realizó en un colegio, de manera presencial, en los horarios

\footnotetext{
${ }^{1}$ Se encuentra disponible a modo de prueba en:

https://docs.google.com/spreadsheet/viewform?formkey=dEdqM3JyeEFHWUxaQmg5THJYL

VBDLVE6MA\#gid=0
} 
de la asignatura de música. Para comprobar la fiabilidad se utilizó la técnica de dos mitades. La correlación de Pearson entre las dos mitades es $r=0,43$; aunque este valor es moderado si se tiene en cuenta que sólo 4 ítems componen la escala se puede aceptar que su fiabilidad es adecuada. Para la realización de la escala de motivación se han tenido en cuenta lo siguientes documentos: Durán (2010), Huertas, Montero y Tapia (1997), Rivero (2009) y Vílchez (2008).

En relación a la encuesta al profesorado, fue enviada por correo electrónico (igual que el enlace para la realización del cuestionario a través de Google Docs) y la realizó por su cuenta. Por tanto, no hubo ninguna relación "cara a cara" entre el entrevistador y entrevistado.

\section{Diseño}

La presente investigación, teniendo en cuenta a Sabariego y Bisquerra (2009), tiene un diseño mixto (combinando herramientas cualitativas y cuantitativas) y es de corte explicativa y descriptiva. Es explicativa porque se indican asociaciones entre variables y la existencia o no de diferencias entre algunas y es descriptiva porque busca analizar la opinión de los alumnos, recabar sus sugerencias, etc.

\section{Análisis de datos}

En primer lugar se realiza el análisis descriptivo de las variables sociodemográficas, actitudes, expectativas, opiniones, preferencias y sugerencias del alumnado. Posteriormente se analizan las asociaciones entre variables que resultan de interés para cumplir con los objetivos de la investigación, en concreto se analizan las siguientes asociaciones mediante $\mathrm{x}^{2}$ de Pearson, se ha utilizado dicha técnica porque las variables son de naturaleza categórica:

- "Nota en música" y "gusto por la asignatura"

- "Internet en casa" y "acceso al blog"

- "Tiempo de uso del blog" y "frecuencia de conexión a internet"

- "Tiempo de uso del blog" e "interés en las TIC"

Posteriormente se han utilizado las pruebas no paramétricas de Mann-Whitney y Kruskal Wallis para estudiar si hay diferencias significativas en las medias de las escalas de actitud, expectativas y motivación según algunas de las características del alumnado: edad, género, gusto por la música, rendimiento en la asignatura, y experiencia con el blog. Finalmente, se ha analizado la entrevista estructurada realizada al profesorado mediante la categorización de respuestas comunes.

\section{Resultados}

\section{Análisis descriptivo general del alumnado}

En cuanto al bloque inicial de información que incluye variables sexo y edad e información sobre la asignatura de música y sobre el uso de las TIC y del blog, se ha 
encontrado que la edad de los participantes está entre los 8 y 13 años aunque el $80 \%$ de los niños tienen entre 10 y 11 años. La distribución por sexos es equitativa $(52,2 \%$ niños y $47,8 \%$ niñas).

Respecto a la asignatura de música un $5,1 \%$ de los alumnos repiten curso, los demás no lo han repetido. A un 70,8\% de los alumnos les gusta la asignatura de música, a un $25,8 \%$ les parece regular y a un $3,4 \%$ no les gusta. En cuanto a la experiencia con el blog de música un $37,1 \%$ lleva utilizándolo un curso, un 23,6\% dos cursos y un 39,3\% cuatro cursos. La distribución porcentual de las notas en la asignatura tanto en el primer como en el segundo trimestre se presentan en la Tabla 1. En cuanto a las variables relacionadas con el uso de las TIC se ha encontrado que a una gran mayoría le gusta usar internet $(97,2 \%)$, también es alto el porcentaje de los que tienen ordenador $(97,8 \%)$ e internet $(92,1 \%)$ en su casa. Un $84,3 \%$ afirman que el ordenador es utilizado por ellos solamente.

\begin{tabular}{|c|c|c|}
\hline & $\mathbf{1}^{\text {er }}$ Trimestre & $\mathbf{2}^{\mathbf{o}}$ Trimestre \\
\hline Sobresaliente & $25,8 \%$ & $32 \%$ \\
\hline Notable & $35,9 \%$ & $33,1 \%$ \\
\hline Bien & $13,5 \%$ & $13,5 \%$ \\
\hline Suficiente & $7,9 \%$ & $5,1 \%$ \\
\hline Insuficiente & $16,9 \%$ & $16,3 \%$ \\
\hline
\end{tabular}

Tabla 1. Notas en la asignatura de Música

En cuanto a las preguntas sobre blog se aprecia que es importante el porcentaje de alumnos que tiene blog propio (20,8\%), un 40,4\% afirma no tener blog propio y un $38,8 \%$ manifiesta interés en crear un blog propio aunque no lo tenga en este momento. A la mayoría de los participantes les gustaría tener blog en otras asignaturas $(61,8 \%)$ a un $30,3 \%$ le da igual y un 7,9\% manifiestan que no les gustaría. La mayoría también se conecta más a internet desde que tiene el blog de música $(66,9 \%)$, mientras que un $30,3 \%$ no lo hace (es decir, no se conecta más desde que usa el blog). Así mismo, un $44,4 \%$ de los alumnos afirman tener mayor interés en las TIC desde que usa el blog de música, un $47,8 \%$ afirman tener el mismo interés y los restantes afirman tener menos interés o no tener interés.

En cuanto a la forma de acceso al blog, un 56,7\% de los encuestados entran al blog solos, un $20,2 \%$ con compañeros de clase, un $12,4 \%$ con padres o hermanos, un $8,4 \%$ con otros familiares y un $2,2 \%$ con amigos. Para terminar este bloque se ha encontrado que la frecuencia de acceso al blog es alta pues más de la mitad (50,5\%) de los alumnos lo hace dos o tres veces a la semana. Un 10,1\% ingresa todos los días, un $15,7 \%$ los días que hay música y sólo un porcentaje muy bajo $(2,2 \%)$ no ha entrado nunca al blog. 


\section{Análisis descriptivo de las actitudes y expectativas del alumnado}

Las actitudes y expectativas del alumnado se han medido en una escala Likert en la que los niños puntuaban cada afirmación desde "muy en desacuerdo" hasta "muy de acuerdo". En general la puntuación en esta escala es alta. Respecto al interés del blog para la asignatura, la mayoría de alumnos $(88,2 \%)$ indicó que el blog es interesante para la asignatura de música, bien estuviera de acuerdo (33,7\%) o muy de acuerdo $(54,5 \%)$. Un $9 \%$ estaba indeciso, mientras que un $2,8 \%$ estaba muy en desacuerdo con ese enunciado. Ningún alumno marcó la posibilidad "en desacuerdo".

Muchos alumnos $(78,09 \%)$ han utilizado el blog para repasar material visto en clase. Los resultados de algunos de los ítems de actitudes y expectativas se presentan en la Tabla 2.

En relación a si le gustaría al alumnado tener un blog, en la tabla 2 se puede ver que el $68 \%$ está a favor de la creación de un blog, los argumentos que han dado los alumnos a dicha pregunta se pueden resumir en: visibilidad del alumno y/o del contenido que publica en el blog (expresarse, etc.); por el placer que produciría tener un blog; formación y/o ayuda al resto de personas; almacenamiento de información de interés para el bloguero (con la posibilidad de verlo por otras personas); marketing; comunicación; imitación a los demás; mostrar sus intereses, opiniones, etc.

En general, las expectativas en torno al blog son buenas (véase Tabla 2). El 82,6 \% considera que el blog le va a ayudar a aprender más en la asignatura. Otras expectativas, que han referido en la parte abierta del cuestionario se pueden resumir en las siguientes categorías: premios y reconocimientos; más material de música; aprendizaje en sentido amplio; herramienta motivadora; herramienta comunicativa y herramienta para trabajo colaborativo.

\begin{tabular}{|l|l|l|l|}
\hline \multicolumn{1}{|c|}{$\begin{array}{c}\text { Le gustaría tener un blog } \\
\text { propio }\end{array}$} & \multicolumn{1}{c|}{$\begin{array}{c}\text { En el blog se encuentran } \\
\text { materiales de la asignatura }\end{array}$} & \\
\hline Muy de acuerdo & $45,5 \%$ & Muy de acuerdo & $78,7 \%$ \\
\hline De acuerdo & $22,5 \%$ & De acuerdo & $14,6 \%$ \\
\hline Indeciso & $16,9 \%$ & Indeciso & $2,2 \%$ \\
\hline En desacuerdo & $5,1 \%$ & En desacuerdo & $2,2 \%$ \\
\hline Muy en desacuerdo & $10,1 \%$ & Muy en desacuerdo & $2,2 \%$ \\
\hline
\end{tabular}




\begin{tabular}{|l|l|l|l|}
\hline $\begin{array}{c}\text { EI blog ayudará a aprender más } \\
\text { en la asignatura }\end{array}$ & \multicolumn{1}{|c|}{$\begin{array}{c}\text { El blog hará que guste más la } \\
\text { asignatura }\end{array}$} & \\
\hline Muy de acuerdo & $61,8 \%$ & Muy de acuerdo & $44,9 \%$ \\
\hline De acuerdo & $20,8 \%$ & De acuerdo & $29,8 \%$ \\
\hline Indeciso & $10,7 \%$ & Indeciso & $15,2 \%$ \\
\hline En desacuerdo & $2,2 \%$ & En desacuerdo & $7,3 \%$ \\
\hline Muy en desacuerdo & $4,5 \%$ & Muy en desacuerdo & $2,8 \%$ \\
\hline
\end{tabular}

Tabla 2. Resultados de algunas preguntas de la dimensión actitudes y expectativas

\section{Análisis descriptivo de las opiniones del alumnado}

La mayoría de los alumnos (86\%) opina que el blog es fácil de utilizar, aproximadamente la mitad $(42,1 \%)$ opina que es necesario que el diseño del blog sea bonito y que le gustaría hacer más cosas con el blog $(45,5 \%)$, como incorporar y usar más material (aunque no sea de la asignatura de música); hacer nuevas actividades o más actividades de las ya realizadas y tener un papel más activo.

A un $77 \%$ le gustaría que el profesor colgara en el blog todo lo que se ve en clase y un $88,2 \%$ opina que aunque se tenga blog, también es necesario cantar, tocar instrumentos, bailar y escuchar música. La mitad de los alumnos piensa que no es necesario que en la asignatura de música cada alumno tenga su blog, se opina más favorablemente sobre un recurso compartido y no individual.

\section{Análisis descriptivo de las preferencias respecto al blog}

Respecto a las preferencias es destacable que un 59,6\% de los encuestados prefiere tener el blog que el libro de texto de música y una gran mayoría $(89,3 \%)$ prefiere hacer las actividades a través del blog que en papel. También es destacable en esta dimensión del cuestionario qué prefería el alumnado tener en su blog. Las frecuencias absolutas de cada alternativa se reflejan en la tabla 3.

La alternativa "Vídeos (de instrumentos, de vosotros, de cantar, bailar, etc.)" fue la más votada, seguida de "Canciones y audiciones de instrumentos", teniendo en tercer lugar a las "Actividades". En el otro extremo, aquello que resultaba de menos interés para el alumnado a la hora de alojarlo en el blog son los "Mapas conceptuales y esquemas". La categorización de las alternativas fue compleja debido a la diversa información disponible en los edublogs seleccionados así como a los diferentes formatos en que podía presentarse. 


\begin{tabular}{|l|l|}
\hline Vídeos (de instrumentos, de vosotros, de cantar, bailar, etc.) & 150 \\
\hline Canciones y audiciones de instrumentos & 132 \\
\hline Historias y cuentos & 28 \\
\hline Dibujos y fotos & 70 \\
\hline Actividades & 114 \\
\hline Enlaces a otras web o blogs (que te lleven directamente a otra web o blog) & 45 \\
\hline Partituras (o vídeos donde vemos las notas musicales) & 90 \\
\hline Apuntes (teoría) & 61 \\
\hline Canciones (o vídeos donde aparecen las letras de las canciones) & 93 \\
\hline Juegos y pasatiempos & 98 \\
\hline Mapas conceptuales y esquemas & 14 \\
\hline
\end{tabular}

Tabla 3. Contenidos que prefieren tener en el blog

\section{Categorización de las sugerencias}

Las sugerencias fueron clasificadas por diseño, uso, contenido y lo que no les gustaba a los alumnos del blog. Algunos ejemplos de sugerencias para el diseño del blog son:

- "Que cambie de vez en cuando el diseño del blog".

- "Está bastante bien, pero le recomendaría poner música de fondo".

- "Me gusta el diseño no tiene que cambiar nada".

Al diseño, los alumnos le modificarían, en algunos casos, el fondo, el diseño, colores más llamativos; aún así, en páginas anteriores se reflejaron los datos sobre qué pensaba el alumnado sobre la necesidad o no de que el diseño del blog fuera bonito.

Algunos ejemplos de sugerencias para el uso del blog:

- "Es sencillo buscar pero si no sabemos la canción es difícil encontrarlo".

- "No es fácil".

- "Es fácil, pero deberían poner búsqueda avanzada". 
En relación a las sugerencias sobre el contenido del blog, algunos ejemplos son los siguientes:

- "Estoy muy satisfecha porque (...) responde a todas nuestras dudas y nos complace en cuanto al contenido".

- "Que ponga más imágenes, vídeos, canciones, informaciones, partituras... (En resumen: Más contenido multimedia).

- "Me da lo mismo".

- "Sobre el contenido es mejor que los apuntes, canciones... (1)as pongáis en los dos sitios porque si se te pierden las tienes en el blog pero al mismo tiempo si vas a algún sitio donde no hay internet no puedes estudiarla o practicarla”.

Y por último, se quería saber qué era lo que no le gustaba al alumnado del blog. Algunos ejemplos son:

- "Los juegos son un poco muy aburridos aunque sirva(n) de ayuda".

- "Que no hay chat".

- "Que se puede meter otra gente".

- "Que no pone cosas divertidas como chistes".

\section{Análisis de asociaciones mediante $x^{2}$ de Pearson}

Las variables que presentan asociación son las siguientes:

- Nota en música. Primer trimestre * ¿Te gusta la asignatura de música? $x^{2}=18,720 ; \mathrm{gl}=8 ; p<0,05$. Cuanto mayor es la nota en el primer trimestre en música mayor es el interés por la asignatura en el alumnado.

- Nota en música. Segundo trimestre * ¿Te gusta la asignatura de música? $x^{2}=22,924 ; \mathrm{gl}=8 ; p<0,05$. Cuanto mayor es la nota en el segundo trimestre en música mayor es el interés por la asignatura en el alumnado.

- ¿Tienes internet en tu casa? * Normalmente, entro en el blog $x^{2}=13,377 ; \mathrm{gl}=4 ; p<0,05$. El acceso a internet en casa se relaciona principalmente con acceder el alumnado de manera individual, solo.

- ¿Cuántos cursos llevas utilizando el blog de música? * ¿Te conectas más a internet desde que usáis el blog en clase de música?

$x^{2}=23,431 ; \mathrm{gl}=4 ; p<0,05$. A mayor cantidad de cursos utilizando el blog mayor utilización de internet.

- ¿Cuántos cursos llevas utilizando el blog de música? * ¿Desde que tienes blogs estás más interesado en las TIC? 
$x^{2}=23,431 ; \mathrm{gl}=4 ; p<0,05$. Cuanta más experiencia en el blog de música más interesado está el alumno en las TIC.

- ¿Cuántos cursos llevas utilizando el blog de música? * Nota en música. Primer trimestre

$\chi^{2}=17,736 ; \mathrm{gl}=8 ; p<0,05$. A más cursos de experiencia con el blog mayor es la nota en música en el primer trimestre.

- ¿Cuántos cursos llevas utilizando el blog de música? * Nota en música. Segundo trimestre

$x^{2}=29,947 ; \mathrm{gl}=8 ; p<0,05$. A más cursos de experiencia con el blog mayor es la nota en música en el segundo trimestre.

Análisis de las escalas de actitud, expectativas y motivación en función de edad, género, gusto por la música y rendimiento en la asignatura

Como se ha dicho anteriormente se han utilizado las pruebas no paramétricas de Mann-Whitney y Kruskal Wallis para estudiar si hay diferencias significativas en las medias de las escalas de actitud, expectativas y motivación según algunas de las características del alumnado como edad, género, gusto por la música y rendimiento en la asignatura. En la tabla 4 se aprecia que no hay diferencias significativas entre sexos ni por edades en ninguna de las tres escalas.

\begin{tabular}{|c|c|c|c|c|}
\hline Variable & & Actitud & Expectativas & Motivación \\
\hline \multirow{4}{*}{ Sexo } & U de Mann-Whitney & 3754 & 3744,5 & 3527,5 \\
\cline { 2 - 5 } & $\mathbf{Z}$ &,- 58 &,- 62 & $-1,25$ \\
\cline { 2 - 5 } & Sig. asintót. (bilateral) &, 56 &, 54 &, 21 \\
\hline \multirow{3}{*}{ Edad } & Chi-cuadrado & 7,921 & 6,11 & 5,65 \\
\cline { 2 - 5 } & Gl & 5 & 5 & 5 \\
\cline { 2 - 5 } & Sig. asintót. (bilateral) &, 56 &, 54 &, 21 \\
\hline
\end{tabular}

Tabla 4. Diferencias en la media de las escalas de actitud, expectativas y motivación de acuerdo a la edad y el sexo

Tampoco hay diferencias significativas en motivación, expectativas y actitud de acuerdo a la nota en música en ninguno de los dos trimestres (tabla 5). 


\begin{tabular}{|c|c|c|c|c|}
\hline Variable & & Actitud & Expectativas & Motivación \\
\hline \multirow{4}{*}{$\begin{array}{c}\text { Notas del } \\
\text { Primer trimestre }\end{array}$} & Chi-cuadrado & 1,74 &, 75 & 2,06 \\
\cline { 2 - 5 } & Gl & 4 & 4 & 4 \\
\cline { 2 - 5 } & Sig. asintót. (bilateral) &, 78 &, 95 &, 73 \\
\hline \multirow{3}{*}{$\begin{array}{c}\text { Notas del } \\
\text { Segundo trimestre }\end{array}$} & Chi-cuadrado & 5,65 & 5,105 & 7,21 \\
\cline { 2 - 5 } & Gl & 4 & 4 & 4 \\
\cline { 2 - 5 } & Sig. asintót. (bilateral) &, 56 &, 54 &, 21 \\
\hline
\end{tabular}

Tabla 5. Diferencias en la media de las escalas de actitud, expectativas y motivación de acuerdo a la nota

En la tabla 6 se puede apreciar que hay diferencias significativas entre las personas que llevan más cursos con el blog y los que llevan menos en las tres escalas. En cuanto a la actitud es más favorable en los alumnos que llevan cuatro cursos utilizando el blog de música (rango $=107,64)$. La relación en cuanto al resto de cursos de experiencia y el rango es la siguiente: 1 curso $(81,27)$ y 2 cursos $(72,19)$. En cuanto a las expectativas el rango mayor $(115,09)$ está también en aquellos alumnos con cuatro cursos de experiencia. La relación en cuanto al resto de cursos de experiencia y el rango es la siguiente: 1 curso $(78,44)$ y 2 cursos $(64,24)$. Por último, en la motivación siguen teniendo el mayor rango los alumnos con una experiencia de cuatro cursos $(105,84)$. La relación en cuanto al resto de cursos de experiencia y el rango es la siguiente: 1 año $(79,97)$ y 2 años $(77,25)$.

También hay diferencias significativas de acuerdo al gusto por la música (ver tabla 6). Tras el análisis de los rangos se puede afirmar que a los alumnos que les gusta la música tienen una actitud mucho más favorable en cuanto al blog (rango promedio $=$ $69,13$ vs rango promedio $=11,17)$; así mismo tienen unas expectativas más favorables (rango promedio $=68,54$ vs rango promedio $=23,58$ ) y una motivación mucho más alta (rango promedio $=68,47$ vs rango promedio $=25,08$ )

\begin{tabular}{|c|c|c|c|c|}
\hline Variable & & Actitud & Expectativas & Motivación \\
\hline \multirow{4}{*}{$\begin{array}{c}\text { Años que lleva } \\
\text { usando el blog }\end{array}$} & Chi-cuadrado & 15,17 & 31,60 & 11,90 \\
\cline { 2 - 5 } & gl & 2 & 2 & 2 \\
\cline { 2 - 5 } & Sig. asintót. (bilateral) &, 001 &, 000 &, 003 \\
\hline \multirow{3}{*}{$\begin{array}{c}\text { Gusto por la } \\
\text { música }\end{array}$} & $\mathbf{U}$ de Mann-Whitney & 46,00 & 120,50 & 129,50 \\
\cline { 2 - 5 } & $\mathbf{Z}$ & $-3,64$ & $-2,88$ & $-2,75$ \\
\cline { 2 - 5 } & Sig. asintót. (bilateral) &, 000 &, 004 &, 006 \\
\hline
\end{tabular}

Tabla 6. Diferencias en la media de las escalas de actitud, expectativas y motivación de acuerdo al gusto por la música y los años que lleva usando el blog. 


\section{Análisis de la entrevista estructurada realizada al profesorado}

\section{Experiencia docente}

La media en relación a los años en el centro donde se está llevando a cabo la investigación son 5,8 años. Su experiencia con edublogs implica varios cursos académicos en la mayoría de los maestro; la media en este aspecto es 3,6 cursos. Como la investigación estaba centrada en blogs concretos del profesorado, también se preguntó el tiempo de experiencia con el edublog participante en la investigación. Aquí la media se reduce, concretamente a 3,5 cursos.

\section{Argumentos para la creación del blog.}

Los principales argumentos que ofrecieron los maestros para la creación del blog son:

- Maestro 1. "Porque lo considero un herramienta imprescindible en mis clases. Porque me motiva a ir creando mi propio material para colgarlo y porque motiva a mis alumnos en su proceso de aprendizaje".

- Maestro 2. "Es una forma llamativa de hacer llegar al alumnado las actividades de la clase de música y de organizar materiales para ahorrar tiempo. Supone también una amplia herramienta de refuerzo y ampliación para el aprendizaje del alumno y, por último, es una puerta al mundo TIC sobre el trabajo que realizamos en clase y sirve para compartir experiencias con otros docentes y blogs".

- Maestro 3. "Es un recurso muy útil para que el alumnado disponga del material necesario para aprender los contenidos de la asignatura y es práctico para tener guardado ese material. El uso del blog sirve como recurso para desarrollar la competencia en TIC".

- Maestro 4. "Me parece una herramienta motivadora, una manera de llevar a casa muchas de las actividades que hacemos en clase (juegos, vídeos, partituras interactivas...), una forma de acercar la clase de música a las familias, de tener ordenados por etiquetas los recursos que encuentro o que elaboro".

- Maestro 5. "No hay mejor lugar para aprovechar la Escuela 2.0 que en el Área de Música. Imagen, sonido, vídeo y palabra dentro de una misma apariencia y estética como en un blog".

- Maestro 6. "El edublog en un inicio pretendía ser un espacio donde mostrar a las familias el trabajo que realizamos en el aula con sus hijos/as. El vídeo es un medio perfecto para mostrar cómo cantan, tocan y bailan los alumnos. Más adelante también se ha convertido en un espacio donde otros maestros pueden ver y compartir recursos y metodologías". 
En cuanto a los objetivos en relación al blog, se han establecido unas dimensiones donde quedan reflejados y son estas, sin ninguna jerarquía pretendida:

- Compartir contenidos y experiencias

- Tomar contacto con las familias

- Reforzar y ampliar lo visto en clase

- Desarrollar la Competencia Digital

- Facilitar el aprendizaje de la música

\section{Metodología del blog}

Ante la pregunta: “iSe enmarca (el blog) dentro de una metodología o se utiliza de manera puntual para determinadas tareas?" Cuatro de los seis maestros lo utilizaban dentro de una metodología, uno de manera puntual y el otro indicó que no se enmarcaba dentro de una metodología: "se utiliza como espacio donde mostrar al máximo las actividades que realizamos". Una respuesta de otro maestro es la siguiente: "es otra herramienta más, no la única e imprescindible para desarrollar el curriculum. Se adapta a las necesidades que se vayan teniendo en cada momento, para actividades globales y para actividades puntuales que necesiten una participación más amplia que la que se pueda aportar en el aula".

De una manera muy superficial se va a mostrar cómo trabajan algunos de los maestros el blog en su clase. Un maestro lo utilizaba casi diariamente en clase de primaria, exceptuando aquellas clases de expresión corporal e instrumentación. Podía utilizarlo al empezar la clase, por ejemplo, para motivar al alumnado, otras veces lo utilizaba al finalizar la misma. Otro maestro indica que en el blog aparecen todas las secciones que trabaja en clase de música. Lo utiliza, por ejemplo, para las canciones a interpretar con la flauta, o para cuestionarios de Historia de la Música. También en el blog cuelga actividades que de manera puntual se trabajan en clase. Otro se sirve de él para iniciar las sesiones de la clase de música, concretamente con una audición alojada en el blog. Al trabajar alguna canción, partitura para flauta, etc., el maestro indica a sus alumnos en qué lugar del blog lo encontrarían. Otro maestro, quien no lo utilizaba en una metodología concreta, mostraba en el blog "un fragmento de cada una de las clases que realizo durante el día".

\section{Ventajas e inconvenientes del blog}

En relación a las ventajas, tal y como se desprende de sus respuestas se ve mejorado, desde el punto de vista del profesorado, el carácter multimedia de los contenidos, la motivación, la ruptura del aprendizaje anclado al espacio físico y temporal del aula, una herramienta para la organización de materiales, etc. Por el contrario, las principales desventajas identificadas son el gran trabajo que implica mantener el blog, y no sólo esta herramienta, sino también los diferentes materiales que en él cuelgan los maestros. Otro aspecto, que también apareció en el 
cuestionario al alumnado, es el acceso a internet. Tanto el alumnado como el profesorado muestran sus quejas en este tema.

\section{Participación del alumnado en el blog}

Un docente indica que la participación del alumnado se limita a la creación de comentarios y a las consultas; en él los alumnos no pueden crear entradas. Otro maestro comenta que la participación del blog es positiva, aunque hay alumnos que no participan en el blog. Otro escribe que la participación es positiva, principalmente para el alumnado de tercer ciclo de educación primaria. Él ha observado que la participación en el blog se ha hecho mayor a medida que el curso se ha acercado a su fin. Un maestro cree que a su alumnado le gusta el blog y accede a él pero hace saber que la participación de los discentes podría ser mayor. Otro hace hincapié en que el alumnado observe el trabajo realizado para que se motiven en la asignatura. Por último, tenemos al sexto maestro que indica que la participación del alumnado se limita a la observación de los vídeos. Manifiesta que incluso es difícil que comenten.

\section{Mejoras realizadas y por realizar}

Las principales mejoras que el profesorado ha realizado en su blog son relacionadas con la organización del mismo. Se han servido de etiquetas para organizar las entradas teniendo en cuenta diferentes aspectos, han incorporado más enlaces a sus blogs, algunos indican que también "gadgets". Algún maestro creó otro blog de manera que sus propios recursos también quedaron organizados. Otro apunta que intenta publicar casi diariamente, etc.

En relación a cuáles son los aspectos que han de mejorar, es decir, que todavía no han sido mejorados, hay un maestro al que le gustaría cambiar su plantilla y también simplificar gadgets. Otro docente pretende conseguir que los comentarios del alumnado queden registrados de manera no anónima y auténtica, y es que en alguna ocasión un alumno ha escrito utilizando el nombre de otro. También quiere crear un apartado en el blog donde mostrar vídeos sobre interpretación de flauta para que los alumnos puedan seguir la digitación de diferentes partituras. Otro habla de mejorar la implicación de su alumnado en relación a los comentarios publicados en el blog así como mejorar la participación en la creación del blog de los alumnos. Se sigue en este aspecto de mejora tratando la organización del blog, donde un maestro quiere organizar las sesiones y programaciones por curso. Por último, hay un maestro que también hace hincapié en mejorar el aspecto de comentarios del alumnado, pero no sólo para que participe el alumnado, sino también su familia. Lo último que indica es alojar en el blog los materiales de los que se sirve en su tarea docente. En lo que más ha incidido el profesorado ha sido en el aspecto de comentarios realizados por parte de sus alumnos.

\section{Qué le permite el blog que no pueda hacer sin él}

La mayor parte de las opiniones recaen en el edublog como repositorio de contenidos y experiencias con la posibilidad de que el alumnado tenga a disposición el material de la clase de música, pudiendo acceder a él fuera del aula y fuero del 
horario escolar. Y esa libertad respecto a un anclaje físico y temporal no sólo se le ofrece al alumnado, también al resto de profesores; así lo ha indicado un maestro. Se ha comentado la motivación y el aspecto más atractivo que presentan los materiales en esta herramienta Web 2.0. Permite adaptarse a los diferentes ritmos de aprendizaje, se convierte en medio de información a las familias de aquello que hacen sus hijos en clase, aunque pueda ser de manera aproximada.

\section{Estrategias para mejorar como blogger}

Se han incluido aspectos como motivar al alumnado, observar blogs de "temática similar", observar tutoriales, investigar otras herramientas. Un maestro habla de ofrecer permisos al alumnado para la edición y que también ellos puedan crear su propio blog. Un docente hace hincapié en la formación para usar el blog.

\section{Conclusiones}

Como se desprende de los resultados de este trabajo el edublog es una herramienta que enriquece el proceso de enseñanza-aprendizaje, tanto por los datos que se desprenden del alumnado como por la opinión del profesorado. No sería acertado atribuirle al blog de manera directa las diversas ventajas que ha aportado a los maestros y alumnos participantes. Más bien se debería entender como un cúmulo de variables, donde se encuentran el blog y algunas otras como podrían ser la metodología llevada a cabo por el profesorado, la actitud de éste frente a la asignatura, la motivación del alumnado, etc. Posiblemente sólo con utilizar el blog, si no existiera un cambio metodológico, no se habrían obtenido estos resultados.

Algunos datos que llevan a afirmar la hipótesis principal de la investigación es que cuanto más tiempo llevan utilizando los alumnos el blog de música mejores son las notas en esta asignatura. Pero no sólo esto, también mayor es el interés por las TIC, y mayor es el uso de internet. La mayoría de los alumnos tienen una motivación alta en relación a esta herramienta de la Web 2.0, como puede desprenderse de los datos, al igual que pasa con las actitudes y expectativas. Se ha visto además que no existen diferencias en la motivación, actitudes y expectativas atendiendo a la edad y el sexo. Tampoco atendiendo a las notas en el primer y segundo trimestre. En cambio, sí existen diferencias en estas dimensiones si tenemos en cuenta la experiencia con el blog y el gusto por la música. Es decir, que a mayor experiencia con el blog e interés por la música mayor es la puntuación del alumnado para esas tres dimensiones.

Se ha encontrado también que la mayoría de los alumnos preferiría tener blog en otras asignaturas. Así, los alumnos ven en esta herramienta un potencial que podría hacerla importante en otras materias. Esto podría deberse a una manera diferente de trabajar a como se hacía en tiempos atrás y más motivadora para el alumnado. Incluso la mayoría de los alumnos acceden al blog de manera regular, pudiendo así tener un mayor contacto con la asignatura que si se utilizasen medios tradicionales. Para la gran mayoría de los alumnos esta herramienta se convierte en un elemento interesante para la asignatura, teniendo así el profesorado ganada esa actitud por parte del alumnado para servirse del blog y enriquecer su trabajo en la escuela con las ventajas que eso 
implicaría para los docentes. Además el blog se utiliza por un gran número de alumnos para el repaso de material de la asignatura.

Pero incluso el blog no sería un elemento propio y limitado sólo al maestro de música, sino que también la mayoría de los alumnos apuestan por la creación de un blog propio. Por tanto, teniendo en cuenta todo lo anterior, se puede llegar a la conclusión que el blog es una herramienta que nos serviría, al menos hasta cierto punto, para mejorar el proceso de enseñanza-aprendizaje y para que los alumnos se familiaricen con las TIC y a partir de ahí vayan profundizando en ellas. Además hemos de tener en cuenta que para la mayoría de los alumnos es una herramienta fácil de usar. Otro factor más a reflejar es que a casi la mitad de los alumnos les gustaría hacer más cosas con el blog de las que ya realizan.

Es de destacar la actitud crítica que posee el alumnado en cuanto a si el blog puede suplir determinadas tareas que exige la asignatura música. La mayoría consideraba que era necesario, por ejemplo, cantar y bailar. Otro aspecto reseñable es que la mayoría de los alumnos prefiere utilizar el blog que el libro de texto de música; incluso prefieren hacer actividades a través del blog que en papel. Aún así, un alumno apuntó que sería mejor tener los materiales de la asignatura (siempre que el formato lo permitiera) tanto en el blog como en papel, para que tuviera acceso a ellos independientemente de la conexión a internet. Otro aspecto a tener en cuenta es que la mayor parte del alumnado entra solo al blog, por lo que debería haber una atención de los padres cuando el alumno acceda de manera general a internet.

El profesorado, también habla de esa capacidad motivadora que tiene el blog, además de permitir almacenar los materiales de la asignatura y etiquetarlos. Se rompe ese anclaje físico y temporal del aula permitiendo que el alumnado se acerque a la música independientemente del lugar y espacio donde se encuentre. Además los maestros hablan del desarrollo de la competencia digital con esta herramienta. Pero como cualquier herramienta, el blog también tiene sus desventajas como se indicó anteriormente. Se podría destacar el acceso a internet que hay en los centros, queja tanto del alumnado como del profesorado. También se necesita tiempo por parte del profesorado no sólo para actualizar el blog, sino para la creación del material que en él se aloja; además de la formación necesaria tal y como se apuntó antes. Un aspecto que en opinión de los docentes debería mejorar por parte de los alumnos son los comentarios que realizan, siendo escasos.

Un punto en el que han coincidido maestros y alumnos es en la capacidad que tiene el blog como elemento democratizador del conocimiento; pudiendo no sólo los alumnos y el profesor aprender del blog con el que trabajan, sino todas aquellas personas que estén interesadas y accedan a él.

Para concluir, el blog no es una panacea en la educación, pero ya se ha visto que el alumnado tiene depositadas en él buenas actitudes, expectativas, motivación, etc., por lo que se convierte en una herramienta que va a facilitar y potenciar el proceso de enseñanza-aprendizaje. Incluso los maestros también están de acuerdo en que es una herramienta que motiva al alumnado, además de atribuirle otras ventajas. Como indicó un maestro en su entrevista: "es otra herramienta más, no la única e imprescindible 
para desarrollar el curriculum". En el presente trabajo se ha visto la asociación de la experiencia en el blog con determinadas variables, en trabajos futuros se puede abordar su relación con otras variables de interés y en otras poblaciones.

\section{Referencias bibliográficas}

ADELL, J. (1997). Tendencias en educación en la sociedad de las tecnologías de la información. Revista Electrónica de Tecnología Educativa, 7. Recuperado de: http://www.uib.es/depart/gte/revelec7.html

BIMBER, B. (2000). Measuring the gender gap on the Internet. Social Science Quarterly, 81(3), 868-876.

BONFADELLI, H. (2002). The Internet and Knowledge Gaps. A Theoretical and Empirical Investigation. European Journal of Communication, 17(1), 65-84.

DIMAGGIO, P., HARGITTAI, E., NEUMAN, W. R., Y ROBINSON, J. P. (2001). Social implications of the internet, 27, 307-336. doi: 10.1146/annurev.soc.27.1.307

DOMINGO, M. Y MARQUÈS, P. (2013). Práctica docente en aulas 2.0 de centros de educación primaria y secundaria de España, Pixel-Bit. Revista de Medios y Educación, 42, 115-128.Recuperado http://acdc.sav.us.es/pixelbit/images/stories/p42/09.pdf

DU, H. Y WAGNER, C. (enero, 2005). Learning with Weblogs: An Empirical Investigation. Trabajo presentado en la 38th Annual Hawaii International Conference on System Sciences (HICSS'05), Universidad de Hawai.

DURÁN, J. F. (2010). La utilización de los edublog en las aulas como dinamizador del proceso de enseñanza-aprendizaje. Revista Docencia e Investigación, 20, 205-243. Recuperado de: http://www.uclm.es/varios/revistas/docenciaeinvestigacion/pdf/numero10/8.pdf

FREGA, A. L. (2005). Música para maestros. Barcelona: Graó.

LIZASO, B. Y GARCÍA, D. (2012). Los edublogs musicales para educación primaria. Música y Educación, 89, 58-69.

GARCÍA, J. L. Y GARCÍA, R. (2012). Aprender entre iguales con herramientas web 2.0 y Twitter en la universidad. Análisis de un caso, EDUTEC, Revista Electrónica de Tecnología Educativa, 40, 1-14. Recuperado de: http://edutec.rediris.es/Revelec2/Revelec40/aprender_entre_iguales_herramientas web2_twitter_universidad.html

GIRÁLDEZ, A. (2010). Repensar la educación musical en un mundo digital. En A. Giráldez (coord.): Música. Complementos de formación disciplinar. Vol. I. Barcelona: Graó.

HEMSY DE GAINZA, V. (1964). La iniciación musical del niño. Buenos Aires: Ricordi. 
HEMSY DE GAINZA, V. (1984). Fundamentos, materiales y técnicas de la educación musical. Buenos Aires: Ricordi.

HUERTAS, J. A., MONTERO, I. Y TAPIA, J. A. (1997). Procedimiento de la evaluación de la motivación humana en J. A. Huertas (coord.): Motivación: Querer aprender. Buenos Aires: Aique.

LARA, T. (2005). Blogs para educar. Uso de los blogs en una pedagogía constructivista, Telos, 65, 86-93. Recuperado de: http://sociedadinformacion.fundacion.telefonica.com/telos/cuadernograbar.asp@ idarticulo $=2 \&$ rev $=65$.

MANEVEAU, G. (1993). Música y Educación. Madrid: Rialp.

MARTÍNEZ, A. Y HERMOSILLA, J. M. (2010). El blog como herramienta didáctica en el espacio europeo de educación superior, Pixel-Bit. Revista de Medios y Educación, 38, 165-175. Recuperado http://www.sav.us.es/pixelbit/actual/13.pdf

MOLINA, J. P., ANTOLÍN, L., PÉREZ-SAMANIEGO, V., DEVÍS-DEVÍS, J., VILLAMÓN, M. Y VALENCIANO, J. (2013). Uso de blogs y evaluación continua del aprendizaje del alumnado universitario, EDUTEC, Revista Electrónica de Tecnología Educativa, 43. Recuperado de: http://edutec.rediris.es/Revelec2/Revelec43/blogs_evaluacion_aprendizaje_alumnad o_u niversitario.html

RIVERO, M. P. (2009). Técnicas de medida y ámbitos de aplicación de la psicología de la motivación en: M. T. Sanz; F. J. Menéndez, M. P. Rivero y M. Conde (Eds), Psicología de la Motivación. Madrid: Sanz y Torres.

SABARIEGO, M. Y BISQUERRA, R. (2009). El proceso de investigación (parte 1) en: Bisquerra, R. (coord.), Metodología de la investigación educativa. Madrid: La Muralla.

SAITTA, C. (1978). Creación e iniciación musical. Buenos Aires: Ricordi.

SANTOS, L. Y FERNÁNDEZ, J. (2012). Uso pedagógico del blog: un proyecto de investigación- acción en la materia de educación física en educación secundaria. EDUTEC, Revista Electrónica de Tecnología Educativa, 42. Recuperado de: http://edutec.rediris.es/Revelec2/Revelec42/uso_pedagogico_blog_proyecto_investi gacion-accion.html

VÍLCHEZ, A. (2008). Test psicométrico para medir el grado de motivación intrínseca. Recuperado de: http://es.scribd.com/doc/17379211/Test

WILLEMS, E. (1994). El valor humano de la educación musical. Barcelona: Paidós Ibérica. 
YANG, C. \& CHANG, Y. (2012). Assessing the effects of interactive blogging on student attitudes towards peer interaction learning motivation, and academic achievements, Journal of Computer Assisted Learning, 28, 126-135.

\section{Correspondencia con los autores}

Sonia Janeth ROMERO MARTÍNEZ

Universidad a Distancia de Madrid

Carretera de la Coruña Km 38,5

Vía de Servicio, $\mathrm{n}^{\circ} 15$

28400 COLLADO VILLALBA - MADRID

e-mail: soniajaneth.romero@udima.es

Teléfono: 653974565 


\section{ANEXO 1}

\section{Cuestionario del alumnado}

\begin{tabular}{|c|}
\hline Datos generales \\
\hline ¿Cuál es tu colegio? \\
\hline ¿Qué edad tienes? \\
\hline $\begin{array}{ll}\text { Sexo: } & \\
& \text { - Hombre } \\
& \text { - Mujer }\end{array}$ \\
\hline $\begin{array}{r}\text { Repito curso: } \\
- \text { Sí } \\
- \text { No }\end{array}$ \\
\hline Nota en música. Primer trimestre: \\
\hline Nota en música. Segundo trimestre: \\
\hline Escribe el nombre de tu ciudad (o pueblo): \\
\hline $\begin{array}{l}\text { ¿Te gusta la asignatura de música?: } \\
\text { - Sí } \\
\text { - No } \\
\text { - Regular }\end{array}$ \\
\hline $\begin{array}{l}\text { ¿Cuántos cursos llevas utilizando el blog de música? (El blog de música en el colegio que estás } \\
\text { ahora): }\end{array}$ \\
\hline $\begin{array}{l}\text { ¿Te gusta usar internet?: } \\
\text { - Sí } \\
\text { - No } \\
\text { - Regular }\end{array}$ \\
\hline $\begin{array}{l}\text { ¿Tienes ordenador en tu casa?: } \\
\text { - Sí } \\
\text { - No }\end{array}$ \\
\hline $\begin{array}{l}\text { ¿Tienes un ordenador que sea sólo para ti? (Que solamente lo utilices tú): } \\
\text { - Sí } \\
\text { - No }\end{array}$ \\
\hline $\begin{array}{l}\text { ¿Tienes internet en tu casa?: } \\
\text { - Sí } \\
\text { - No }\end{array}$ \\
\hline $\begin{array}{l}\text { ¿Tienes un blog? (Un blog que sea tuyo, no el de clase de música): } \\
\text { - Sí } \\
\text { - No } \\
\text { - No, pero me gustaría hacerme uno }\end{array}$ \\
\hline $\begin{array}{l}\text { ¿Te gustaría tener blog en otras asignaturas?: } \\
\text { - Sí } \\
\text { - No } \\
\text { - Me da igual tener que no tener blog en otras asignaturas }\end{array}$ \\
\hline $\begin{array}{l}\text { ¿Te conectas más a internet desde que usáis el blog en clase de música?: } \\
\text { - Sí } \\
\text { - No } \\
\text { - Sólo me conecto a internet para ver el blog de música }\end{array}$ \\
\hline $\begin{array}{l}\text { ¿Desde que tienes blogs estás más interesado en las TIC? Las TIC son los ordenadores, internet, iPad, } \\
\text { etc.: } \\
\quad \text { - No tengo interés por las TIC } \\
\text { - Tengo menos interés }\end{array}$ \\
\hline
\end{tabular}




\begin{tabular}{|c|c|c|c|c|c|}
\hline \multicolumn{6}{|c|}{$\begin{array}{l}\text { - Tengo el mismo interés } \\
\text { - Tengo más interés }\end{array}$} \\
\hline \multicolumn{6}{|c|}{$\begin{array}{l}\text { Normalmente, accedo al blog: } \\
\text { - Todos los días } \\
\text { - Todos los días que tengo clase de música } \\
\text { - Dos o tres veces a la semana } \\
\text { - Una vez al mes } \\
\text { - Dos o tres veces al mes } \\
\text { - Una vez cada varios meses } \\
\text { - Todavía no he entrado en el blog }\end{array}$} \\
\hline \multicolumn{6}{|c|}{$\begin{array}{l}\text { Normalmente, entro en el blog: } \\
\text { - Yo solo } \\
\text { - Con compañeros y amigos de clase } \\
\text { - Con otros amigos que no son de clase (ni del colegio) } \\
\text { - Con mis padres o hermanos } \\
\text { - Con familiares }\end{array}$} \\
\hline \multicolumn{6}{|c|}{$\begin{array}{c}\text { Actitudes en cuanto al blog } \\
\text { En este caso, la actitud es el ánimo que tú tienes en el blog de música. }\end{array}$} \\
\hline & $\begin{array}{l}\text { 1. Muy en } \\
\text { desacuerdo }\end{array}$ & $\begin{array}{c}\text { 2. En } \\
\text { desacuerdo }\end{array}$ & 3. Indeciso & 4. De acuerdo & $\begin{array}{c}\text { 5. Muy } \\
\text { de } \\
\text { acuerdo }\end{array}$ \\
\hline \multicolumn{6}{|l|}{$\begin{array}{c}\text { El blog es interesante } \\
\text { para la asignatura de } \\
\text { música }\end{array}$} \\
\hline \multicolumn{6}{|l|}{$\begin{array}{c}\text { Si yo fuera maestro, } \\
\text { utilizaría un blog en } \\
\text { mi clase }\end{array}$} \\
\hline \multicolumn{6}{|l|}{$\begin{array}{l}\text { Me gusta (o gustaría) } \\
\text { comentar en el blog }\end{array}$} \\
\hline \multicolumn{6}{|l|}{$\begin{array}{l}\text { Ofrezco (o quiero } \\
\text { ofrecer) cosas al } \\
\text { maestro para que } \\
\text { cuelgue en el blog }\end{array}$} \\
\hline \multicolumn{6}{|l|}{$\begin{array}{l}\text { Suscribirme al blog es } \\
\text { interesante (al } \\
\text { suscribirte al blog te } \\
\text { llega a tu correo } \\
\text { electrónico las cosas } \\
\text { nuevas que se pongan } \\
\text { en el blog) } \\
\end{array}$} \\
\hline \multicolumn{6}{|l|}{$\begin{array}{l}\text { Me gustaría tener un } \\
\text { blog propio (tú te } \\
\text { haces un blog de lo } \\
\text { que te guste, todo el } \\
\text { mundo lo puede ver } \\
\text { en internet) }\end{array}$} \\
\hline \multicolumn{6}{|c|}{$\begin{array}{l}\text { Si en la pregunta anterior has puesto que te gustaría tener un blog (si has puesto una puntuación de } 4 \text { o } \\
\text { 5) indica por qué. }\end{array}$} \\
\hline $\begin{array}{c}\text { En el blog puedo } \\
\text { encontrar muchas } \\
\text { cosas de la asignatura } \\
\text { (por ejemplo, }\end{array}$ & & & & & \\
\hline
\end{tabular}




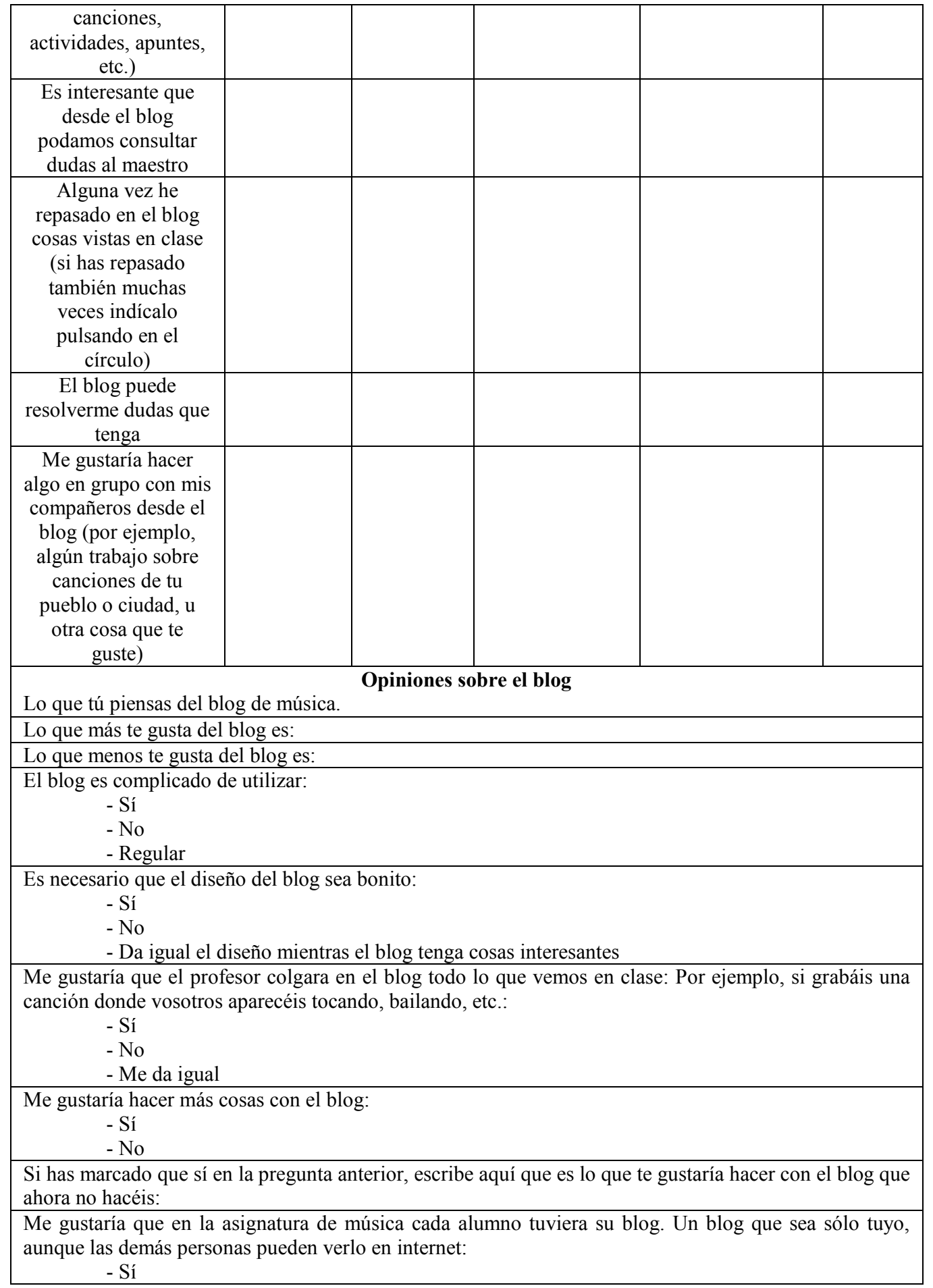




\begin{tabular}{|c|c|c|c|c|c|}
\hline \multicolumn{6}{|l|}{$\begin{array}{l}\text { - No } \\
\text { - No es ned }\end{array}$} \\
\hline \multicolumn{6}{|c|}{$\begin{array}{l}\text { Aunque tengamos blog, también es necesario cantar, tocar instrumentos, bailar, escuchar música, etc.: } \\
\text { - Sí, es necesario cantar, bailar, etc. } \\
\text { - No, no es necesario cantar, bailar, etc. }\end{array}$} \\
\hline \multicolumn{6}{|c|}{$\begin{array}{l}\text { Expectativas con el blog } \\
\text { Las expectativas son qué crees que vas a conseguir. Aquí se refiere a qué crees que vas a conseguir con } \\
\text { el blog. }\end{array}$} \\
\hline & $\begin{array}{l}\text { 1. Muy en } \\
\text { desacuerdo }\end{array}$ & $\begin{array}{c}\text { 2. En } \\
\text { desacuerdo }\end{array}$ & 3. Indeciso & 4. De acuerdo & $\begin{array}{l}\text { 5. Muy de } \\
\text { acuerdo }\end{array}$ \\
\hline \multicolumn{6}{|l|}{$\begin{array}{l}\text { El blog me va a } \\
\text { ayudar a aprender } \\
\text { más en la asignatura }\end{array}$} \\
\hline \multicolumn{6}{|l|}{$\begin{array}{l}\text { El blog hará que me } \\
\text { guste más la } \\
\text { asignatura }\end{array}$} \\
\hline $\begin{array}{l}\text { El blog me ayudará a } \\
\text { aprender a navegar } \\
\text { por internet (quiere } \\
\text { decir, que al usar el } \\
\text { blog, tú aprenderás a } \\
\text { meterte en diferentes } \\
\text { sitios de internet) }\end{array}$ & & & & & \\
\hline \multicolumn{6}{|c|}{ Qué más crees que va a conseguir con el blog: } \\
\hline
\end{tabular}

Prefiero tener el blog que tener el libro de texto de música. El libro de texto de música es el "libro normal" de música. Igual que tienes otro libro (a lo mejor no) de matemáticas, etc.:

- Sí, prefiero tener el blog y no libro de música

- No, prefiero tener libro de música y no tener blog

- Prefiero tener las dos cosas, blog y libro de música

Prefiero tener en el blog vídeos y audios (por ejemplo canciones) que tener imágenes y textos:Con textos me refiero a tener frases, historias, apuntes, etc.:

- Sí, prefiero tener vídeos y audios

- No, prefiero tener imágenes y textos

- Prefiero tener vídeos, audios, imágenes y textos

Prefiero solamente observar el blog que participar en él. Con participar me refiero a comentar, darle al profesor material para que cuelgue en el blog, etc.:

- Sí, prefiero sólo observar el blog

- No, prefiero observar el blog y participar en él

Prefiero hacer actividades a través del blog que en papel (en la libreta, folios, etc.):

- Sí, prefiero hacerlas en el blog

- No, prefiero hacerlas en papel

Prefiero que el maestro cuelgue los apuntes (o temas a estudiar) en el blog que tenerlos en la libreta o folios:

- Sí, prefiero tenerlos en el blog

- No, prefiero tenerlos en la libreta o folios

Prefiero que el maestro cuelgue en el blog las partituras (o canciones) que tenerlas en papel (libreta, folios, etc.):

- Sí, prefiero tenerlas en el blog

- No, prefiero tenerlas en papel

De manera general, prefiero que lo que aprenda (letras de canciones, partituras, apuntes, etc.) esté en el 
blog en vez de tenerlo en la libreta, folios o libros:

- Sí, prefiero tenerlo en el blog

- No, prefiero tenerlo en papel

Marca SÓLO 5 PALABRAS de aquello que prefieres tener en el blog. Primero lee todos y luego pincha en cada cuadrado:

- Vídeos (de instrumentos, de vosotros, de cantar, bailar, etc.)

- Canciones y audiciones de instrumentos

- Historias y cuentos

- Dibujos o fotos

- Actividades

- Enlaces a otras web o blogs (que te lleven directamente a otra web o blog)

- Partituras (o vídeos donde vemos las notas musicales)

- Apuntes (teoría)

- Canciones (o vídeos donde aparecen las letras de las canciones))

- Juegos y pasatiempos

- Mapas conceptuales y esquemas

Qué puedes decirle a tu maestro para que lo mejore.

En cuanto al diseño (aspecto del blog):

En cuanto al uso (navegar por él, por ejemplo, si es fácil o difícil utilizar el blog):

En cuanto al contenido (lo que tiene el blog):

Indica lo que no te gusta del blog:

\begin{tabular}{|c|c|c|c|c|c|}
\hline \multicolumn{7}{|c|}{ Motivación en cuanto al blog } \\
\hline $\begin{array}{c}\text { Me interesa usar el } \\
\text { blog }\end{array}$ & $\begin{array}{c}\text { 1. Muy en } \\
\text { desacuerdo }\end{array}$ & $\begin{array}{c}\text { 2. En } \\
\text { desacuerdo }\end{array}$ & 3. Indeciso & 4. De acuerdo & $\begin{array}{c}\text { 5. Muy de } \\
\text { acuerdo }\end{array}$ \\
\hline $\begin{array}{c}\text { Todas las semanas } \\
\text { veo el blog (no } \\
\text { cuenta cuando lo } \\
\text { ves en clase de } \\
\text { música) }\end{array}$ & & & & & \\
\hline $\begin{array}{c}\text { Estoy atento al blog } \\
\text { porque me gusta lo } \\
\text { que aparece en él }\end{array}$ & & & & & \\
\hline $\begin{array}{c}\text { Mi actitud frente al } \\
\text { blog es buena }\end{array}$ & & & & & \\
\hline
\end{tabular}




\section{ANEXO 2 \\ Entrevista estructurada del profesorado}

1. Nombre del centro escolar:
2. Años que lleva como maestro en el centro escolar donde se está realizando la investigación:
3. Cursos de experiencia con edublogs:
4. Cursos de experiencia con el edublog que participa en la investigación:
5. Cursos de experiencia con el edublog que participa en la investigación (esta pregunta concreta
se refiere a si el edublog lleva desde sus comienzos en el centro donde se encuentra ahora o el
mismo edublog ya se utilizó en otro centro anteriormente):
6. Indique (en no más de dos frases) por qué utiliza edublog.
7. Cuáles son los objetivos que se pretenden con el edublog:
8. iSe enmarca dentro de una metodología o se utiliza de manera puntual para determinadas
tareas?:
9. Si el blog se utiliza dentro de una metodología, indique su manera de trabajar con él (indique
también la frecuencia de uso del blog, de manera general):
10. Ventajas principales del uso del edublog (indicarlas por orden de preferencia):
11. Inconvenientes principales del uso del edublog (indicarlas por orden de preferencia):
12. Cómo considera la participación del alumnado en el blog:
13. Aspectos de mejora realizados en el blog:
14. Aspectos de mejora a realizar en el blog:
15. Qué le permite llevar a cabo el edublog que no podría realizar sin él:
16. Indique qué "estrategia" o tareas se pueden llevar a cabo para mejorar como blogger
(entendiéndolo desde el punto de vista del edublog):
17. Si sabe la opinión de los padres en cuanto al uso del edublog en clase de música (o de las TIC
en general) indíquelo:
18. Indique su idea de educación musical (lo que entiende por ella, o cómo tiene que llevarse a
cabo, etc.):
19. Indique aquello a lo que le da prioridad en clase de música (ya sea cantar, tocar la flauta, etc.),
20. Indique lo que cree que más le gusta al alumnado (ya sea cantar, tocar la flauta, etc.), donde el
21. Observaciones (escriba aquello que no quede reflejado en las preguntas realizadas o lo que
considere importante):

